\title{
QUEEN'S
UNIVERSITY
BELFAST
}

\section{In Situ Study of Li Intercalation into Highly Crystalline Graphitic Flakes of Varying Thicknesses}

Zou, J., Sole, C., Drewett, N. E., Velicky, M., \& Hardwick, L. J. (2016). In Situ Study of Li Intercalation into Highly Crystalline Graphitic Flakes of Varying Thicknesses. Journal of Physical Chemistry Letters, 7(21), 4291-4296. https://doi.org/10.1021/acs.jpclett.6b01886

Published in:

Journal of Physical Chemistry Letters

Document Version:

Publisher's PDF, also known as Version of record

Queen's University Belfast - Research Portal:

Link to publication record in Queen's University Belfast Research Portal

Publisher rights

Copyright (C) 2016 American Chemical Society

This is an open access article published under a Creative Commons Attribution (CC-BY)

http://pubs.acs.org/page/policy/authorchoice_ccby_termsofuse.html

License, which permits unrestricted use, distribution and reproduction in any medium, provided the author and source are cited.

\section{General rights}

Copyright for the publications made accessible via the Queen's University Belfast Research Portal is retained by the author(s) and / or other copyright owners and it is a condition of accessing these publications that users recognise and abide by the legal requirements associated with these rights.

Take down policy

The Research Portal is Queen's institutional repository that provides access to Queen's research output. Every effort has been made to ensure that content in the Research Portal does not infringe any person's rights, or applicable UK laws. If you discover content in the Research Portal that you believe breaches copyright or violates any law, please contact openaccess@qub.ac.uk. 


\title{
In Situ Study of Li Intercalation into Highly Crystalline Graphitic Flakes of Varying Thicknesses
}

\author{
Jianli Zou, ${ }^{\dagger}$ Christopher Sole, ${ }^{\dagger}$ Nicholas E. Drewett, $^{\dagger}$ Matěj Velický, ${ }^{\dagger}$ and Laurence J. Hardwick ${ }^{*}{ }^{\dagger}$ \\ ${ }^{\dagger}$ Stephenson Institute for Renewable Energy, Department of Chemistry, University of Liverpool, Liverpool L69 7ZD, United \\ Kingdom \\ ${ }^{\ddagger}$ School of Chemistry, University of Manchester, Oxford Road, Manchester M13 9PL, United Kingdom
}

Supporting Information

ABSTRACT: An in situ Raman spectroelectrochemical study of Li intercalation into graphite flakes with different thicknesses ranging from $1.7 \mathrm{~nm}$ (3 graphene layers) to $61 \mathrm{~nm}$ (ca. 178 layers) is presented. The lithiation behavior of these flakes was compared to commercial microcrystalline graphite with a typical flake thickness of $\sim 100 \mathrm{~nm}$. Li intercalation into the graphitic flakes was observed under potential control via in situ optical microscopy and Raman spectroscopy. As graphite flakes decreased in thickness, a Raman response indicative of increased tensile strain along the graphene sheet was observed during the early stages of intercalation. A progressively negative wavenumber shift of the interior and bounding modes of the split $G$ band $\left(E_{2 g_{2}}(i)\right.$ and $\left.E_{2 g_{2}}(b)\right)$ is interpreted as a weakening of the $\mathrm{C}-\mathrm{C}$ bonding. Raman spectra of $\mathrm{Li}$ intercalation into thin graphitic flakes are

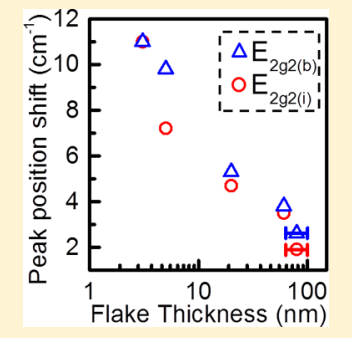
presented and discussed in the context of implications for $\mathrm{Li}$ ion battery applications, given that intercalation induced strain may accelerate carbon negative electrode aging and reduce long-term cycle life.

$\mathrm{R}$ echargeable lithium ion batteries represent the leading energy storage technology solution for many applications such as portable electronics, power tools, and electric vehicles and represent strong considerations for various grid storage systems. ${ }^{1,2}$ In commercial $\mathrm{Li}$ ion devices, bulk graphite is the most widely used anode material due to its cost-effective performance. $\mathrm{Li}$ intercalation into graphite proceeds via a series of staged graphite intercalation compounds (GICs), classified by stage index $n$, whereby $n$ represents the number of graphene layers separating intercalated ions. The first- and/or secondorder Raman spectra of graphitic carbons during the first lithiation and delithiation have been investigated in a typical lithium ion battery electrolyte by us ${ }^{3-5}$ and others ${ }^{6,7}$ in order to understand $\mathrm{Li}$ intercalation into practical carbon electrodes. In situ Raman spectroscopic measurements under potential control enable probing of the graphitic negative electrode during ion insertion and extraction. Experimental results reveal typical staging formation on different regions of the electrode surface from the splitting of the $G$ band $\left(1580 \mathrm{~cm}^{-1}\right)$ into a doublet band. ${ }^{7}$ The lower $\left(\mathrm{E}_{2 \mathrm{~g} 2}(\mathrm{i})\right)$ and upper $\left(\mathrm{E}_{2 \mathrm{~g} 2}(\mathrm{~b})\right)$ frequency components are correspondingly associated with carbon atom vibrations in interior graphite layers (not adjacent to the intercalate layer planes) and in bounding graphite layers (adjacent to the intercalate planes). The split in the $G\left(E_{2 g_{2}}\right)$ mode upon intercalation occurs primarily from changes in symmetry at the boundary layer and secondarily from the electronic effects of the intercalate molecule. The $\mathrm{E}_{2 \mathrm{~g} 2}(\mathrm{i})$ band disappears for stages 1 and 2, where no graphite interior layer exists.

Recent research interest in graphene has led to a variety of studies on the chemical doping of single-layer graphene (SLG) and intercalation of guest species into few-layer graphene systems. For example, in situ Raman spectroscopy has been used to monitor the doping (intercalation) of single-layer (bilayer) graphene with rubidium vapor. ${ }^{8}$ In another study, the intercalation of ferric chloride $\left(\mathrm{FeCl}_{3}\right)$ into graphite flakes consisting of 2-4 graphene layers has also been characterized by Raman spectroscopy. ${ }^{9}$ Nevertheless, despite the fact that LiGICs have been extensively studied since the 1970 s, ${ }^{10-16}$ the difference in the electrochemical lithiation process with various graphene layer thicknesses is still not well understood. A number of authors have recently applied Raman spectroscopy to understand the lithiation mechanism for graphenic materials. Pollak et al. ${ }^{17}$ studied the interaction of $\mathrm{Li}$ with few-layer graphene and concluded that the process seems to resemble that of bulk graphite. However, recent work ${ }^{18}$ suggested that $\mathrm{Li}$ intercalation into a few layers of graphene showed a strong dependence on the number of graphene layers, as measured via stationary voltammetry.

Herein, we present an in situ Raman spectroelectrochemical study of $\mathrm{Li}$ intercalation into edges of highly crystalline graphite with different thicknesses ranging from $1.7 \mathrm{~nm}$ (3 graphene layers) to $61 \mathrm{~nm}$ (ca. 178 layers). The lithiation behavior of these flakes was compared to that of commercial microcrystalline graphite (60-100 nm thick), and it was observed that with decreasing flake thickness, the downshift of both $\mathrm{E}_{2 \mathrm{~g} 2}(\mathrm{i})$ and $\mathrm{E}_{2 \mathrm{~g} 2}(\mathrm{~b})$ bands increases, which is indicative of additional tensile strain upon the graphene sheets during ion insertion.

Highly crystalline natural graphite flakes (NGS Naturgraphit $\mathrm{GmbH}$ ) were mechanically exfoliated onto a borosilicate glass

Received: August 21, 2016

Accepted: October 14, 2016

Published: October 14, 2016 
a)

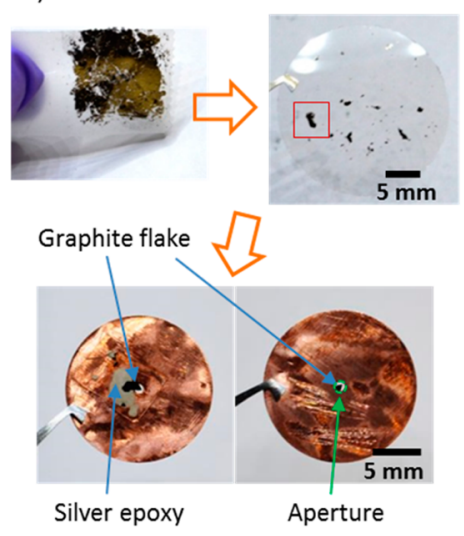

b)

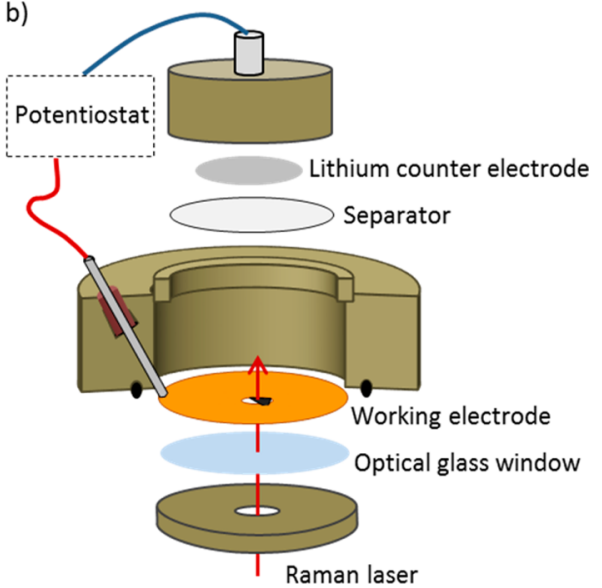

Figure 1. Schematic illustration of the assembly of graphite flakes into the in situ spectroelectrochemical Raman cell. (a) Graphite flakes were mechanically exfoliated onto a borosilicate glass cover slide. A single graphite flake was selected, isolated using a diamond-tipped glass cutter, and connected to a copper current collector using silver epoxy, ensuring that the area of interest was aligned with the aperture in the center for direct observation. (b) The copper-glass sandwich with the contacted graphite flake (working electrode) was assembled in an EL-CELL electrochemical test cell (ECC-Opto-Std) with the silver epoxy on the opposite side of the current collector to the electrolyte-impregnated separator.
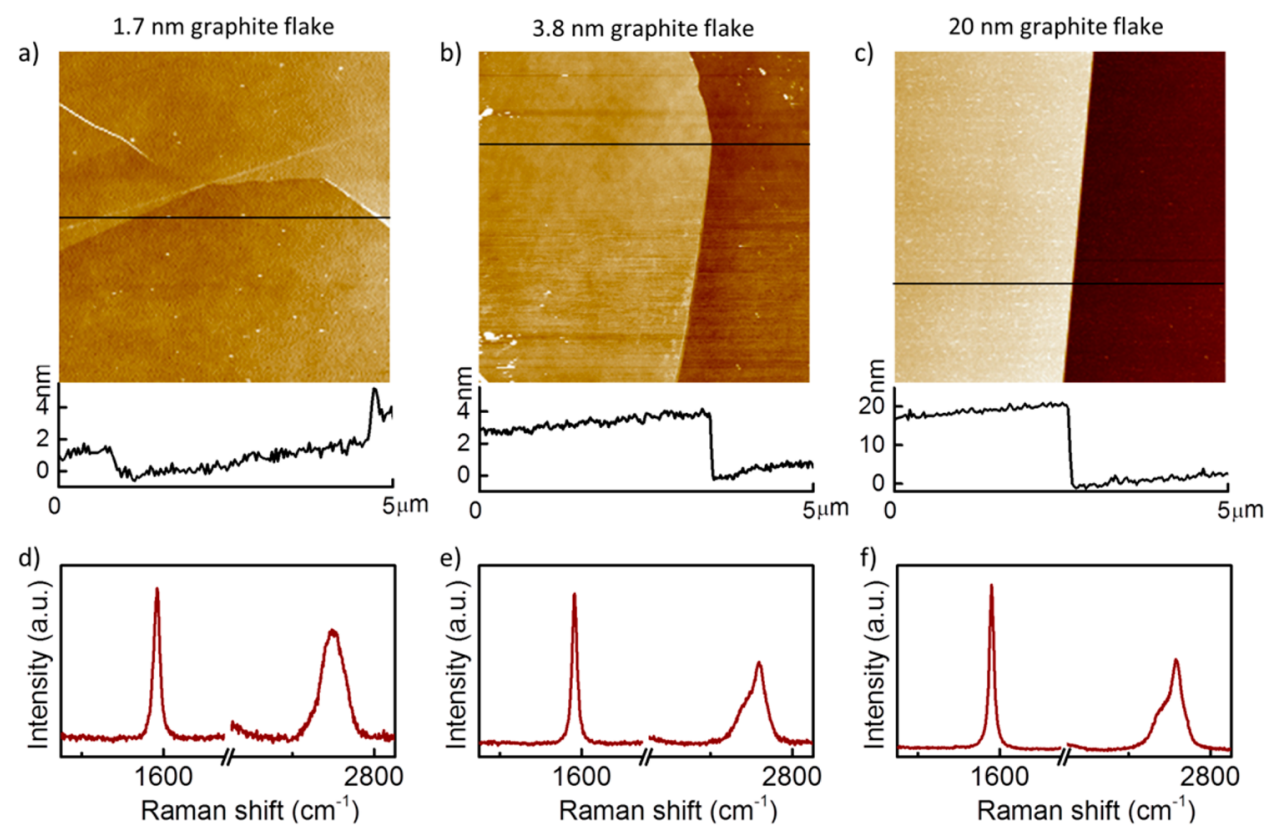

Figure 2. Characterization of graphite flakes by AFM and Raman spectroscopy. (a-c) AFM images and the height profiles of three graphite flakes with thicknesses of $1.7 \mathrm{~nm}$ ( 3 graphene layers), $3.8 \mathrm{~nm}$ (9 graphene layers), and $20 \mathrm{~nm}$ (ca. 56 graphene layers). (d-f) Corresponding Raman spectra of the graphite flakes shown in $(a-c)$.

cover slide using the "Scotch tape method" ${ }^{19,20}$ Flakes were selected according to the following requirements: ideal flakes should possess a thin flat region of several square micrometers area to allow facile Raman analysis, while the whole flake should be bigger than a few hundred micrometers and thick enough $(>500 \mathrm{~nm})$ at one edge to facilitate electronic connection using silver epoxy. Figure 1a illustrates the sample fabrication process and its formation into an electrode for the in situ spectroelectrochemical Raman cell. Graphitic flake thicknesses were determined by atomic force microscopy (AFM). Silver epoxy was used to make an electronic connection between the graphitic flake and the copper current collector, leaving the area of interest pristine. The position of the flake was aligned to coincide with the small aperture (ca. $1 \mathrm{~mm}$ diameter) made in the center of the copper current collector for direct optical observation. The silver epoxy contact was positioned facing the glass window in order to minimize possible contact with the electrolyte. The graphite flake electrode was assembled in an EL-CELL spectroelectrochemical Raman cell (ECC-Opto-Std). Figure $1 \mathrm{~b}$ shows the simplified version of the configuration of the test cell, with graphite flake acting as the working electrode and $\mathrm{Li}$ metal as the counter electrode. A free-standing microcrystalline flake graphite electrode was prepared as described previously (IMERYS, SFG6; the typical flake thickness, estimated from SEM images of the microcrystalline graphite, is between 60 and $100 \mathrm{~nm}$, Figure S1). ${ }^{3} \operatorname{LiPF}_{6}(1 \mathrm{M})$ in $1: 1 \mathrm{w} / \mathrm{w}$ ethylene carbonate/dimethyl carbonate (BASF) was used as the electrolyte. Cyclic voltammetry was performed using a potentiostat (Biologic) to induce electrochemical intercalation of the graphite samples. Initially, the cell was 
discharged at $0.02 \mathrm{mV} / \mathrm{s}$ from open-circuit voltage (OCV) to $1.2 \mathrm{~V}\left(\mathrm{vs} \mathrm{Li}^{+} / \mathrm{Li}\right)$, and then, a slower rate of $0.005 \mathrm{mV} / \mathrm{s}$ was employed between 1.2 and $0.005 \mathrm{~V}$ vs $\mathrm{Li}^{+} / \mathrm{Li}$, while Raman spectra were collected at room temperature (ca. $23{ }^{\circ} \mathrm{C}$ ) (Renishaw inVia, laser wavelength $532 \mathrm{~nm},<19 \mathrm{~kW} / \mathrm{cm}^{2}$ ). Due to the slow scan rate employed, changes during lithiation of the graphite sample occurred on the time scale of the spectral acquisitions, allowing spectra to be collected at a quasiequilibrium state. Furthermore, unless otherwise stated, all Raman measurements were taken a few micrometers from the flake edge to reduce/mitigate differences arising from inhomogeneous $\mathrm{Li}$ diffusion induced by defects and grain boundaries within the crystalline flake. The successful electronic connection to the graphitic flakes was confirmed by the observation of $\mathrm{Li}$ intercalation though optical visualization of the well-documented phenomena of color changes in the flake and corresponding Raman spectra, relating to staged $\mathrm{Li}$ insertion (Figure S2). ${ }^{21-24}$

Figure 2 shows the AFM images, height profile, and Raman characterization of three representative graphite flakes used in this study. The thicknesses were $1.7 \mathrm{~nm}$ (Figure 2a), $3.8 \mathrm{~nm}$ (Figure 2b), and $20 \mathrm{~nm}$ (Figure 2c), corresponding to 3 graphene layers, 9 graphene layers, and $\sim 56$ graphene layers, respectively. Raman spectroscopy is a powerful analytical tool for study of both GICs and few-layer graphene, and it is a key tool to probe the physical and electronic properties in graphene-based materials. ${ }^{10,25-27}$ Analysis of the two main signals in the Raman spectra, the $G$ band at around $1582 \mathrm{~cm}^{-1}$ and the dispersive double resonance peak in the range between 2600 and $2700 \mathrm{~cm}^{-1}$ (2D band), offers detailed information; for example, it allows determination of the number of graphene layers, induced strain in the structure, and charging. ${ }^{28}$ The Raman spectra of all three graphite flakes exhibit two intense peaks: a G band at $\sim 1582 \mathrm{~cm}^{-1}$ and a $2 \mathrm{D}$ band at $\sim 2700 \mathrm{~cm}^{-1}$ for the three-layer sample and $\sim 2718 \mathrm{~cm}^{-1}$ for other thicker flakes (Figure $2 \mathrm{~d}-\mathrm{f}$ ). The absence of a D band at $\sim 1350 \mathrm{~cm}^{-1}$ indicates the very low defect density in our mechanically exfoliated natural graphite samples.

Figure 3 shows in situ Raman spectra of microcrystalline flake graphite and graphite flakes with three different thicknesses $(1.7,3.8$, and $20 \mathrm{~nm}$ ) during lithiation. During $\mathrm{Li}$ insertion for all samples, the $2 \mathrm{D}$ band was observed to shift to lower wavenumbers, accompanied by the decrease of intensity, as has previously been recorded. ${ }^{3}$ The intercalation behavior of 20 and $3.8 \mathrm{~nm}$ thick graphite flakes displays similar characteristics to that of microcrystalline flake graphite. A clear split of the $G$ band to $E_{2 \mathrm{~g} 2}(\mathrm{i})$ and $\mathrm{E}_{2 \mathrm{~g} 2}(\mathrm{~b})$ modes at around $0.22 \mathrm{~V}$ was preceded by an upshift in the $G$ band frequency. The splitting of the $\mathrm{G}$ band can be interpreted as the graphene layers next to intercalated $\mathrm{Li}$ layers being differentiated from those adjacent to empty galleries, according to the nearest-layer model of Nemanich and Solin. ${ }^{16}$

In contrast, the $1.7 \mathrm{~nm}$ (3 layers) graphitic edge flake showed rather different behavior as a definitive $G$ band split was not observed during lithiation (although this was difficult to fully resolve due to the low initial OCV intensity signal, as shown in Figure S3). The 2D band vanished into the background noise at a relatively high potential (not detectable by $0.19 \mathrm{~V}$ ), after an initial measurable downshift from 2718 to $2704 \mathrm{~cm}^{-1}$. Within the three graphene layers, formation of stages 3 and 4 during lithiation is not possible; therefore, it can be concluded from Raman data that lithiation occurs directly via dilute stage 1 GIC to stage 1 . In contrast, splitting of the $\mathrm{G}$ band was observed in a
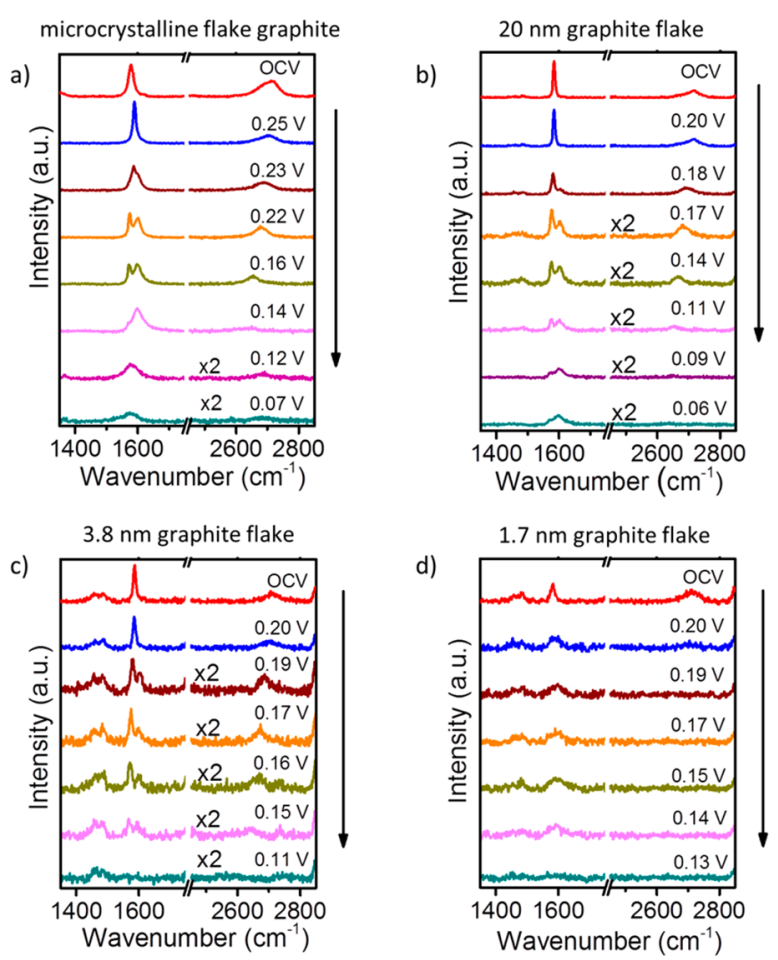

Figure 3. Raman spectra during lithiation of (a) microcrystalline flake graphite with $\sim 60-100 \mathrm{~nm}$ thickness and graphite flakes with (b) 20 $\mathrm{nm}$ (ca. 56 graphene layers), (c) $3.8 \mathrm{~nm}$ (9 graphene layers), and (d) $1.7 \mathrm{~nm}$ (3 graphene layers) thicknesses. The OCV was $\sim 2.9 \mathrm{~V}$, all potentials quoted measured vs $\mathrm{Li}^{+} / \mathrm{Li}$ (see Figure S3 for the comparison of the $\mathrm{G}$ peak intensity at the $\mathrm{OCV}$ ).

previous study whereby a three-graphene-layer sample was chemically doped by $\mathrm{NO}_{2}$ adsorption. ${ }^{29}$ In this case, $\mathrm{G}$ peak splitting arose as only the surface layers were doped, leaving the interior layers undoped. In Figure 3d, no obvious splitting is observed as all three layers are adjacent to $\mathrm{Li}$ ions, suggesting that during the intercalation process $\mathrm{Li}$ ions are distributed in both available interlayer spaces. It should be noted that with respect to all single flake measurements reported in this study, it is not possible to completely distinguish whether the $\mathrm{Li}$ ions insert directly at the studied flake edge/electrolyte interface or have diffused into the thinner flake from being initially intercalated into the bulk graphite crystal.

In order to further compare the results, the peak position of the $\mathrm{G}$ band was plotted versus the potential in Figures 4 and S4. All samples experienced an upshift in $\mathrm{G}$ band frequency before the splitting occurred, as previously observed below $\sim 0.2 \mathrm{~V}$ vs $\mathrm{Li}^{+} / \mathrm{Li}^{3,24,30}$ This upshift can be understood by considering the doping effect during the dilute stage 1 phase in all samples. The stiffening of the $E_{2 g 2}$ phonon with doping has been previously explained by an increase in the force constants of in-plane $\mathrm{C}-\mathrm{C}$ bonds, while similar behavior has been observed in SLG. ${ }^{31}$ Interestingly, the upshift is more prominent for the microcrystalline flake graphite compared to all single flake samples. Upshifts of the $\mathrm{G}$ band ( $\mathrm{ca} .10 \mathrm{~cm}^{-1}$ ) have been observed previously by us ${ }^{3}$ and Shi et al. ${ }^{30}$ Dilute stage 1 formation is responsible for between 4 and $7 \%$ of the theoretical capacity of graphite ( 20 vs $372 \mathrm{~mA} \mathrm{~h} / \mathrm{g})$; $^{11}$ thus, the lower doping in this region for our single flake samples suggests that the proportion of $\mathrm{Li}$ insertion during the dilute stage 1 GIC phase decreases as the flake thickness of graphite particles is reduced. 

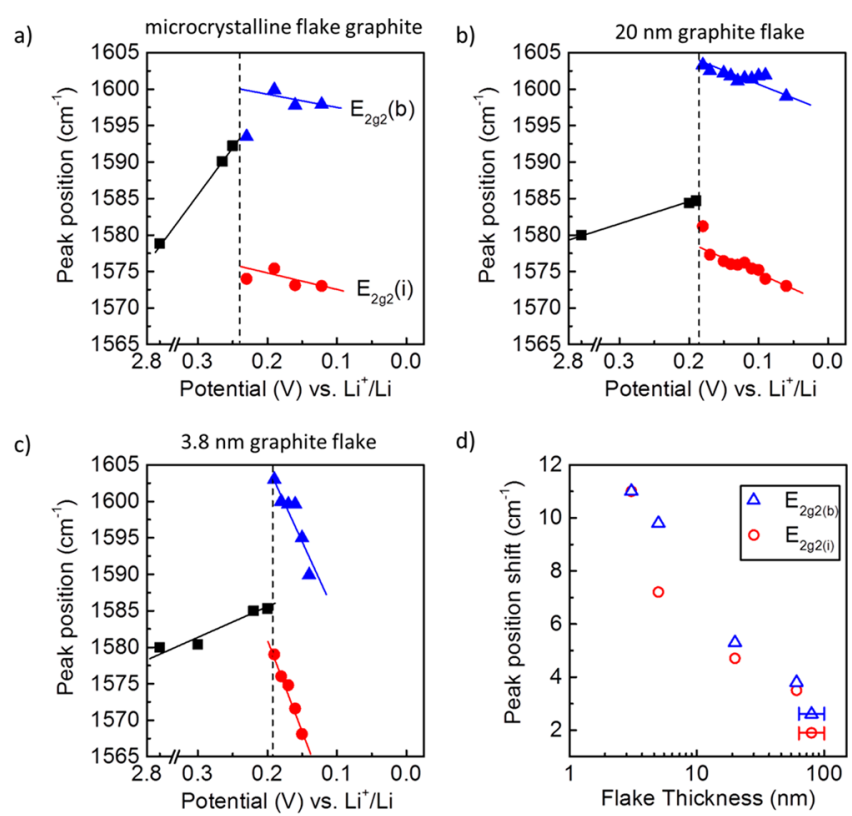

Figure 4. Peak position of the $G$ band during intercalation for (a) microcrystalline flake graphite, (b) $20 \mathrm{~nm}$ graphite flakes, and (c) 3.8 $\mathrm{nm}$ graphite flakes. The dashed line indicates when splitting occurred. (d) Comparison of the Raman peak shift of the split G band for graphite flakes with different thicknesses.

The $G$ band then splits into the $E_{2 g 2}(i)$ peak at lower wavenumber and the $\mathrm{E}_{2 \mathrm{~g} 2}(\mathrm{~b})$ peak at higher wavenumber, indicated by the dashed line in Figure 4. Significantly, as the intercalation progresses, both $\mathrm{E}_{2 \mathrm{gg} 2}(\mathrm{i})$ and $\mathrm{E}_{2 \mathrm{~g} 2}(\mathrm{~b})$ downshift, showing the trend whereby the thinner the flake, the steeper the slope of the shift from $0.2 \mathrm{~V} \mathrm{vs} \mathrm{Li}^{+} / \mathrm{Li}$ onward. The downshift in the band position can be considered to be the result of biaxial tensile strain, as has been previously observed. ${ }^{27,32}$ Electron doping of the graphene sheets causes occupation of the $\pi^{*}$ antibonding band, which produces a weakening and elongation of the intralayer $\mathrm{C}-\mathrm{C}$ bonds within the graphene sheets. ${ }^{33-35}$

Figure $4 \mathrm{~d}$ compares the Raman peak shift of the split $\mathrm{G}$ band for graphite flakes of different thicknesses (see Figure S4 for the peak position of the $G$ band during intercalation for 61 and 5 $\mathrm{nm}$ thick graphite flakes). The $\mathrm{E}_{2 \mathrm{~g}_{2}}(\mathrm{~b})$ position shifts up to 11 $\mathrm{cm}^{-1}$ for the $3.8 \mathrm{~nm}$ flake and down to $2.6 \mathrm{~cm}^{-1}$ for the microcrystalline flake graphite, corresponding to the stage 4 to stage 3 transition. The shift in the $\mathrm{G}$ peak position $\left(\Delta \omega_{\mathrm{E}_{28}}\right)$ with biaxial tensile strain $(\varepsilon)$ is given by

$$
\Delta \omega_{\mathrm{E}_{2 \mathrm{~g} 2}}=-2 \omega_{\mathrm{E}_{2 \mathrm{~g} 2}}^{0} \gamma_{\mathrm{E}_{2 \mathrm{~g} 2}} \varepsilon
$$

where $\omega_{\mathrm{E}_{282}}^{0}$ is the Raman frequency of unstrained graphene and $\gamma_{\mathrm{E}_{2 g^{2}}}$ is the Grüneisen parameter. Mohiuddin et al. ${ }^{32}$ determined $\gamma_{\mathrm{E}_{28}}=1.99$, causing a $-63 \mathrm{~cm}^{-1}$ shift in the $\mathrm{G}$ band position per $\%$ biaxial strain. This shift is constant regardless of flake thickness; therefore, the biaxial strain in the microcrystalline flake graphite and the $3.8 \mathrm{~nm}$ flake can be calculated as 0.04 and $0.17 \%$ respectively. The data therefore suggest an increase in the strain as the thickness of the flakes decreases, meaning that the increase in $\mathrm{C}-\mathrm{C}$ bond lengths is greater with decreasing flake thickness, as shown in Figure 4d. Previous measurements have shown that the $\mathrm{C}-\mathrm{C}$ bond length increases by $\sim 1.0 \%$ upon lithiation of bulk graphite to $\mathrm{LiC}_{6}$, with $\mathrm{C}-\mathrm{C}$ bond lengths of 1.421 and $1.435 \AA$, respectively. ${ }^{36,37}$ At first glance, the calculated values for the increased tensile strain and bond length increase do not appear to be too remarkable and may not seem to be relevant for technological applications. However, Li ion battery graphitic anodes have shown an increase of graphitic disorder (as indicated by an increase of $\mathrm{D}$ band intensity with respect to the $G$ band) after repeated shallow cycling, even with the assumption of $0.04 \%$ increase in tensile strain. ${ }^{38}$ The surface of the graphite anode undergoes gradual structural degradation upon cycling, and this effect has been reported to occur generally in all graphitic carbons. ${ }^{38-40}$ During aging of the anode, a damaged graphite surface consumes the cycleable Li inventory via further solid electrolyte interphase formation on the freshly exposed carbon surface. ${ }^{41}$ Thereby, an increase to $0.17 \%$ biaxial tensile strain could lead to more rapid graphitic disordering during repeated $\mathrm{Li}$ insertion/ extraction cycles, suggesting that there may be an optimum range of flake thickness for long-lifetime graphitic $\mathrm{Li}$ ion anodes.

Analysis of the Raman spectra for intercalation into the three-layer graphene flake provides further evidence that the $G$ band position is a sum of the competing processes of dopinginduced upshift and strain-induced downshift (Figure 5). The
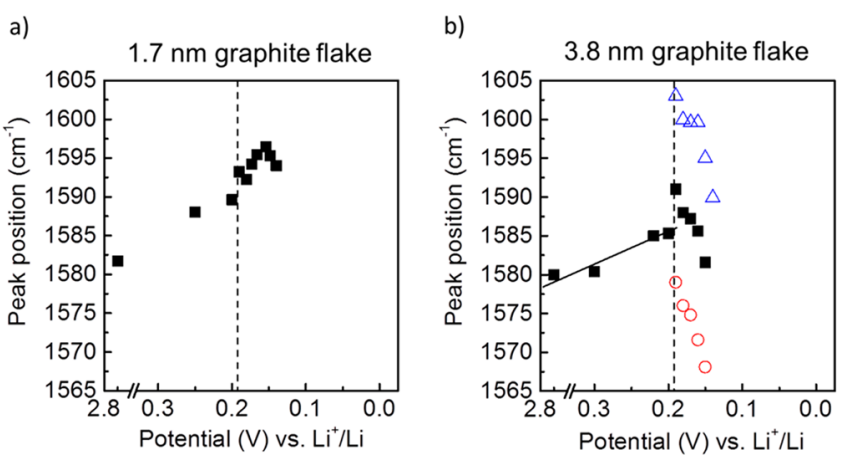

Figure 5. Comparison of the G peak position of (a) $1.7 \mathrm{~nm}(3$ graphene layers) and (b) $3.8 \mathrm{~nm}$ (9 graphene layers) graphite flakes during lithiation. The blue and red cycles in (b) are the real data of $E_{2 g 2(i)}$ and $E_{2 g 2(b)}$, and the solid squares (after the dashed line) represent the arithmetic mean value of both $E_{2 g 2}$ bands. The dash line in (a) indicates where the $G$ peak splits in $b$ ).

initial upshift of the $G$ band position is again observed, concurrent with the formation of dilute stage 1 , which continues until $\sim 0.15 \mathrm{~V}$ when it begins downshifting and then loses observable intensity. The lack of obvious splitting, as discussed earlier, suggests a bypassing of the conventional stage 4 and stage 3 formation and continuation of dilute stage 1 until the later stages of intercalation. Significantly, a similar trend of $\mathrm{G}$ band position suggests the competing influence of upshift caused primarily by electron doping and subsequent downshift due to significant biaxial strain. This is highlighted in Figure 5 where the mean $\mathrm{G}$ band position of the nine-layer graphite flake is plotted alongside the $\mathrm{G}$ band of the three-layer graphite sample. The trend of arithmetic mean values of $\mathrm{E}_{2 \mathrm{~g} 2}(\mathrm{i})$ and $\mathrm{E}_{2 \mathrm{~g} 2}(\mathrm{~b})$ peak positions showed a close resemblance to the $\mathrm{G}$ band position in the three-layer graphite flake. This similar trend is also shown in other thickness flakes (Supporting Information Figure S5).

The $2 \mathrm{D}$ band is known to be a more sensitive indicator of strain than the G band. ${ }^{25,32}$ Similarly to previous studies, ${ }^{3,28}$ we observe a clear downshift of the $2 \mathrm{D}$ band followed by a loss of 
all observable intensity. Figure 6 shows the shift in the 2D band position, from the first spectra where a split $G$ peak is observed

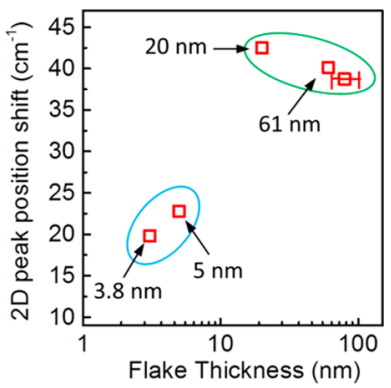

Figure 6. 2D peak position shift from the first spectra where a split G peak is observed until the last spectra in which the $2 \mathrm{D}$ band remains detectable above the signal noise for samples of $3.8 \mathrm{~nm}$ (9 graphene layers), $5 \mathrm{~nm}$ (ca. 13 graphene layers), $20 \mathrm{~nm}$ (ca. 56 graphene layers), $61 \mathrm{~nm}$ (ca. 178 graphene layers), and microcrystalline flake graphite (ca. $60-100 \mathrm{~nm}$ ) during lithiation.

for each sample until the last spectra in which the 2D band remains visible. For samples thicker than $5 \mathrm{~nm}$, a large downshift of the $2 \mathrm{D}$ band is observed (ca. $40 \mathrm{~cm}^{-1}$ ), yet below $10 \mathrm{~nm}$ thickness, the $2 \mathrm{D}$ band shift is significantly less. The downshift has previously been ascribed to a combination of doping and tensile strain, suggesting that one of these factors is lessened for the thinner single flake samples. However, previous studies have shown that electron doping also causes a rapid decrease in $2 \mathrm{D}$ band intensity. ${ }^{42,43}$ Due to the reduced signal to background intensity of the thinner single flake samples (Figure S3), this causes the disappearance of the $2 \mathrm{D}$ band at earlier potentials (Figure 3), which results in smaller observed 2D band shifts. Therefore, although a difference in $2 \mathrm{D}$ band behavior with flake thickness is observed, it is not possible to draw strong conclusions regarding strain and doping to support those from the reported $\mathrm{G}$ band analysis.

In summary, electrochemical lithiation in large graphitic flakes with different thicknesses ranging from $\sim 100 \mathrm{~nm}$ down to three graphene layers thick has been systemically studied via in situ Raman spectroscopy. With decreasing flake thickness, a Raman response indicative of increased tensile strain during the early stages of $\mathrm{Li}$ intercalation, when compared to thicker (60$100 \mathrm{~nm}$ ) commercial microcrystalline graphite flakes, was detected. As intercalation induced strain is one of the causes of battery capacity fade during long-term cycling, due to gradual disordering of graphitic anodes, this study highlights the possible increase of the rate of graphite degradation if thinner flakes are used within commercial Li ion cells. Further analysis is required to clarify the impact on aging via multiple $\mathrm{Li}$ insertion/extraction cycles of graphitic negative electrodes (anodes) consisting of flakes thinner than $20 \mathrm{~nm}$.

\section{ASSOCIATED CONTENT}

\section{S Supporting Information}

The Supporting Information is available free of charge on the ACS Publications website at DOI: 10.1021/acs.jpclett.6b01886.

Preparation of the microcrystalline flake graphite electrode method, SEM image of microcrystalline flake graphite, intercalation dynamics discussion and optical microscopy images, comparison of the absolute Raman intensity of samples at the open-current voltage, G band position shift for 61 and $5 \mathrm{~nm}$ thick graphite flake, and comparison of the position of the split G band arithmetic mean for all samples (PDF)

\section{AUTHOR INFORMATION}

\section{Corresponding Author}

*E-mail: hardwick@liverpool.ac.uk.

\section{Notes}

The authors declare no competing financial interest.

\section{ACKNOWLEDGMENTS}

We acknowledge the Engineering and Physical Sciences Research Council (EPSRC) for funding of this research under Grant Number EP/K016954.

\section{REFERENCES}

(1) Tarascon, J. M.; Armand, M. Issues and Challenges Facing Rechargeable Lithium Batteries. Nature 2001, 414, 359-367.

(2) Goodenough, J. B.; Park, K.-S. The Li-Ion Rechargeable Battery: A Perspective. J. Am. Chem. Soc. 2013, 135, 1167-1176.

(3) Sole, C.; Drewett, N. E.; Hardwick, L. J. In Situ Raman Study of Lithium-Ion Intercalation into Microcrystalline Graphite. Faraday Discuss. 2014, 172, 223-237.

(4) Sole, C.; Drewett, N. E.; Liu, F.; Abdelkader, A. M.; Kinloch, I. A.; Hardwick, L. J. The Role of Re-Aggregation on the Performance of Electrochemically Exfoliated Many-Layer Graphene for Li-Ion Batteries. J. Electroanal. Chem. 2015, 753, 35-41.

(5) Hardwick, L. J.; Buqa, H.; Novák, P. Graphite Surface Disorder Detection Using in Situ Raman Microscopy. Solid State Ionics 2006, 177, 2801-2806.

(6) Migge, S.; Sandmann, G.; Rahner, D.; Dietz, H.; Plieth, W. Studying Lithium Intercalation into Graphite Particles via in Situ Raman Spectroscopy and Confocal Microscopy. J. Solid State Electrochem. 2005, 9, 132-137.

(7) Inaba, M.; Yoshida, H.; Ogumi, Z. In Situ Raman Study of Electrochemical Lithium Insertion into Mesocarbon Microbeads HeatTreated at Various Temperatures. J. Electrochem. Soc. 1996, 143, 2572-2578.

(8) Parret, R.; Paillet, M.; Huntzinger, J.-R.; Nakabayashi, D.; Michel, T.; Tiberj, A.; Sauvajol, J.-L.; Zahab, A. A. In Situ Raman Probing of Graphene over a Broad Doping Range upon Rubidium Vapor Exposure. ACS Nano 2013, 7, 165-173.

(9) Zhao, W.; Tan, P. H.; Liu, J.; Ferrari, A. C. Intercalation of FewLayer Graphite Flakes with $\mathrm{FeCl} 3$ : Raman Determination of Fermi Level, Layer by Layer Decoupling, and Stability. J. Am. Chem. Soc. 2011, 133, 5941-5946.

(10) Dresselhaus, M. S.; Dresselhaus, G. Intercalation Compounds of Graphite. Adv. Phys. 2002, 51, 1-186.

(11) Dahn, J. R. Phase Diagram of $\mathrm{Li}_{\mathrm{x}} \mathrm{C}_{6}$. Phys. Rev. B: Condens. Matter Mater. Phys. 1991, 44, 9170-9177.

(12) Yazami, R.; Touzain, P. A Reversible Graphite-Lithium Negative Electrode for Electrochemical Generators. J. Power Sources 1983, 9, 365-371.

(13) Yamada, Y.; Takazawa, Y.; Miyazaki, K.; Abe, T. Electrochemical Lithium Intercalation into Graphite in Dimethyl Sulfoxide-Based Electrolytes: Effect of Solvation Structure of Lithium Ion. J. Phys. Chem. C 2010, 114, 11680-11685.

(14) Yamada, Y.; Furukawa, K.; Sodeyama, K.; Kikuchi, K.; Yaegashi, M.; Tateyama, Y.; Yamada, A. Unusual Stability of Acetonitrile-Based Superconcentrated Electrolytes for Fast-Charging Lithium-Ion Batteries. J. Am. Chem. Soc. 2014, 136, 5039-5046.

(15) Yamada, Y.; Yaegashi, M.; Abe, T.; Yamada, A. A Superconcentrated Ether Electrolyte for Fast-Charging Li-Ion Batteries. Chem. Commun. 2013, 49, 11194-11196.

(16) Solin, S. A. Graphite Intercalation Compounds; Springer-Verlag: Berlin, Germany, 1990. 
(17) Pollak, E.; Geng, B.; Jeon, K.-J.; Lucas, I. T.; Richardson, T. J.; Wang, F.; Kostecki, R. The Interaction of Li with Single-Layer and Few-Layer Graphene. Nano Lett. 2010, 10, 3386-3388.

(18) Hui, J.; Burgess, M.; Zhang, J.; Rodríguez-López, J. Layer Number Dependence of $\mathrm{Li}^{+}$Intercalation on Few-Layer Graphene and Electrochemical Imaging of Its Solid-Electrolyte Interphase Evolution. ACS Nano 2016, 10, 4248-4257.

(19) Novoselov, K. S.; Geim, A. K.; Morozov, S. V.; Jiang, D.; Zhang, Y.; Dubonos, S. V.; Grigorieva, I. V.; Firsov, A. A. Electric Field Effect in Atomically Thin Carbon Films. Science 2004, 306, 666-669.

(20) Novoselov, K. S.; Jiang, D.; Schedin, F.; Booth, T. J.; Khotkevich, V. V.; Morozov, S. V.; Geim, A. K. Two-Dimensional Atomic Crystals. Proc. Natl. Acad. Sci. U. S. A. 2005, 102, 1045110453.

(21) Maire, P.; Evans, A.; Kaiser, H.; Scheifele, W.; Novák, P. Colorimetric Determination of Lithium Content in Electrodes of Lithium-Ion Batteries. J. Electrochem. Soc. 2008, 155, A862-A865.

(22) Maire, P.; Kaiser, H.; Scheifele, W.; Novák, P. Colorimetric Determination of Lithium-Ion Mobility in Graphite Composite Electrodes. J. Electroanal. Chem. 2010, 644, 127-131.

(23) Harris, S. J.; Timmons, A.; Baker, D. R.; Monroe, C. Direct in Situ Measurements of Li Transport in Li-Ion Battery Negative Electrodes. Chem. Phys. Lett. 2010, 485, 265-274.

(24) Inaba, M.; Yoshida, H.; Ogumi, Z.; Abe, T.; Mizutani, Y.; Asano, M. In Situ Raman Study on Electrochemical Li Intercalation into Graphite. J. Electrochem. Soc. 1995, 142, 20-26.

(25) Ferrari, A. C.; Basko, D. M. Raman Spectroscopy as a Versatile Tool for Studying the Properties of Graphene. Nat. Nanotechnol. 2013, $8,235-246$.

(26) Malard, L. M.; Pimenta, M. A.; Dresselhaus, G.; Dresselhaus, M. S. Raman Spectroscopy in Graphene. Phys. Rep. 2009, 473, 51-87.

(27) Chacón-Torres, J. C.; Wirtz, L.; Pichler, T. Raman Spectroscopy of Graphite Intercalation Compounds: Charge Transfer, Strain, and Electron-Phonon Coupling in Graphene Layers. Phys. Status Solidi B 2014, 251, 2337-2355.

(28) Chacón-Torres, J. C.; Wirtz, L.; Pichler, T. Manifestation of Charged and Strained Graphene Layers in the Raman Response of Graphite Intercalation Compounds. ACS Nano 2013, 7, 9249-9259.

(29) Crowther, A. C.; Ghassaei, A.; Jung, N.; Brus, L. E. Strong Charge-Transfer Doping of 1 to 10 Layer Graphene by $\mathrm{NO}_{2}$. ACS Nano 2012, 6, 1865-1875.

(30) Shi, Q.; Dokko, K.; Scherson, D. A. In Situ Raman Microscopy of a Single Graphite Microflake Electrode in a $\mathrm{Li}^{+}$-Containing Electrolyte. J. Phys. Chem. B 2004, 108, 4789-4793.

(31) Pisana, S.; Lazzeri, M.; Casiraghi, C.; Novoselov, K. S.; Geim, A. K.; Ferrari, A. C.; Mauri, F. Breakdown of the Adiabatic BornOppenheimer Approximation in Graphene. Nat. Mater. 2007, 6, 198201.

(32) Mohiuddin, T. M. G.; Lombardo, A.; Nair, R. R.; Bonetti, A.; Savini, G.; Jalil, R.; Bonini, N.; Basko, D. M.; Galiotis, C.; Marzari, N.; et al. Uniaxial Strain in Graphene by Raman Spectroscopy: G Peak Splitting, Grüneisen Parameters, and Sample Orientation. Phys. Rev. B: Condens. Matter Mater. Phys. 2009, 79, 1-8.

(33) Kertesz, M. Changes of Lattice Geometries Upon Charge Transfer. Mol. Cryst. Liq. Cryst. 1985, 126, 103-110.

(34) Nixon, D. E.; Parry, G. S. The Expansion of the Carbon-Carbon Bond Length in Potassium Graphites. J. Phys. C: Solid State Phys. 1969, 2, 1732-1741.

(35) Pietronero, L.; Strassler, S. Bond-Length Change as a Tool to Determine Charge Transfer and Electron-Phonon Coupling in Graphite Intercalation Compounds. Phys. Rev. Lett. 1981, 47, 593596.

(36) Billaud, D.; Henry, F. X.; Lelaurain, M.; Willmann, P. Revisited Structures of Dense and Dilute Stage II Lithium-Graphite Intercalation Compounds. J. Phys. Chem. Solids 1996, 57, 775-781.

(37) Guerard, D.; Herold, A. Intercalation of Lithium into Graphite and Other Carbons. Carbon 1975, 13, 337-345.
(38) Sethuraman, V. A.; Hardwick, L. J.; Srinivasan, V.; Kostecki, R. Surface Structural Disordering in Graphite upon Lithium Intercalation/Deintercalation. J. Power Sources 2010, 195, 3655-3660.

(39) Kostecki, R.; McLarnon, F. Microprobe Study of the Effect of Li Intercalation on the Structure of Graphite. J. Power Sources 2003, 119$121,550-554$.

(40) Markervich, E.; Salitra, G.; Levi, M. D.; Aurbach, D. Capacity Fading of Lithiated Graphite Electrodes Studied by a Combination of Electroanalytical Methods, Raman Spectroscopy and SEM. J. Power Sources 2005, 146, 146-150.

(41) Hardwick, L. J.; Marcinek, M.; Beer, L.; Kerr, J. B.; Kostecki, R. An Investigation of the Effect of Graphite Degradation on Irreversible Capacity in Lithium-Ion Cells. J. Electrochem. Soc. 2008, 155, A442A447.

(42) Chen, C.-F.; Park, C.-H.; Boudouris, B. W.; Horng, J.; Geng, B.; Girit, C.; Zettl, A.; Crommie, M. F.; Segalman, R. A.; Louie, S. G.; et al. Controlling Inelastic Light Scattering Quantum Pathways in Graphene. Nature 2011, 471, 617-620.

(43) Cohn, A. P.; Share, K.; Carter, R.; Oakes, L.; Pint, C. L. Ultrafast Solvent-Assisted Sodium Ion Intercalation into Highly Crystalline Few-Layered Graphene. Nano Lett. 2016, 16, 543-548. 